\title{
Application of low-cost fine particulate mass monitors to convert satellite aerosol optical depth to surface concentrations in North America and Africa
}

\section{Carl Malings et al.}

Correspondence to: Carl Malings (cmalings@alumni.cmu.edu) and R. Subramanian (subu@cmu.edu)

The copyright of individual parts of the supplement might differ from the CC BY 4.0 License. 


\section{S1 Ground-based Monitoring Sites}

Table S1: Seasonal definitions. Temperature and humidity columns indicate the averages for the season, along with the interquartile range in parenthesis. Data were obtained from internal temperature and humidity sensors within the RAMP monitors deployed to each area. Statistics were computed for the spatial averages of temperature and humidity across all

5 RAMP locations within each area which were active during the time period in question.

\begin{tabular}{|c|c|c|c|c|c|}
\hline Season & Area & Start & End & $\begin{array}{c}\text { Temperature } \\
{\left[{ }^{\circ} \mathbf{C}\right]}\end{array}$ & $\begin{array}{c}\text { Humidity } \\
{[\%]}\end{array}$ \\
\hline Winter & Pittsburgh & Jan. 01, 2018 & Feb. 28, 2018 & $1(-5$ to 7$)$ & $74(66$ to 83$)$ \\
\hline Spring & Pittsburgh & Mar. 01, 2018 & May 31, 2018 & $12(3$ to 20) & $64(52$ to 77$)$ \\
\hline Summer & Pittsburgh & June 01, 2018 & Aug. 31, 2018 & $25(21$ to 29) & $69(59$ to 80$)$ \\
\hline Fall & Pittsburgh & Sep. 01, 2018 & Dec. 31, 2018 & $11(3$ to 20) & 77 (70 to 86) \\
\hline Wet Season 1 & Rwanda & Apr. 01, 2017 & June 14, 2017 & $23(19$ to 26) & $67(57$ to 78$)$ \\
\hline Dry Season 1 & Rwanda & June 15, 2017 & Sep. 14, 2017 & $22(19$ to 26) & $52(43$ to 61) \\
\hline Wet Season 2 & Rwanda & Sep. 15, 2017 & Dec. 14, 2017 & $22(18$ to 26) & $65(55$ to 77$)$ \\
\hline Dry Season 2 & Rwanda & Dec. 15, 2017 & Feb. 13, 2018 & $23(19$ to 26) & $67(55$ to 78) \\
\hline Wet Season 3 & Rwanda & Feb. 14, 2018 & May 31, 2018 & $21(17$ to 23) & $75(65$ to 85$)$ \\
\hline
\end{tabular}

a)

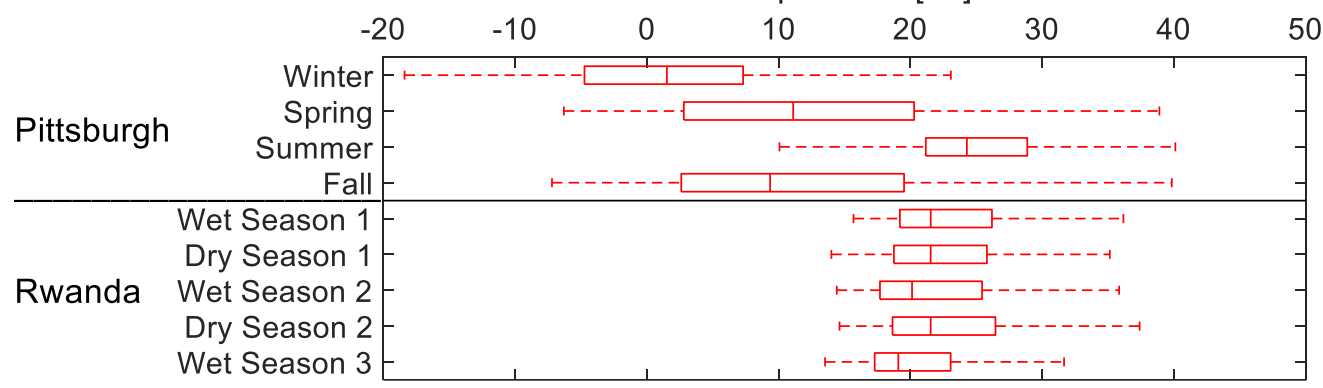

b)

Relative Humidity [\%]

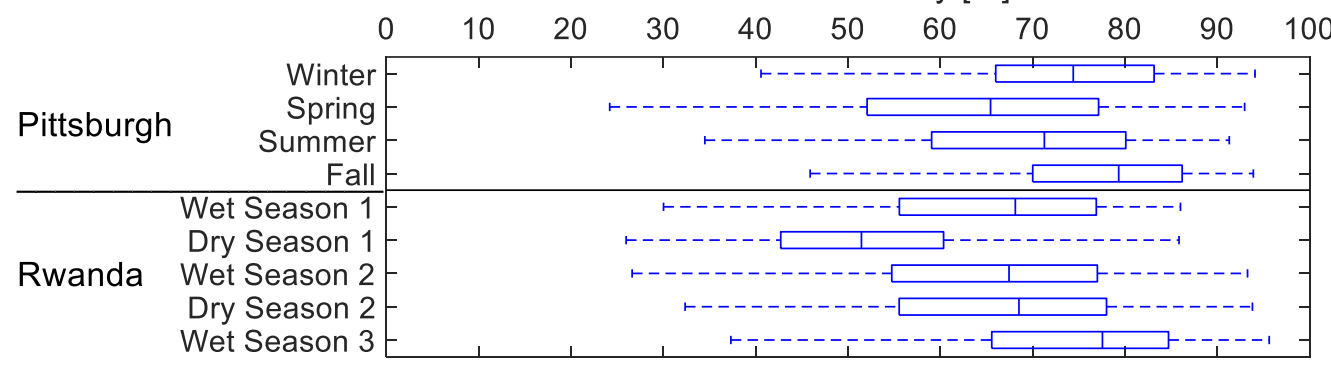

Figure S1: Box plots of seasonal temperature (a) and relative humidity (b) data for Pittsburgh and Rwanda. Data are obtained from internal temperature and humidity sensors within the RAMP monitors deployed in each area. Data represent 10 hourly temperature and humidity values averaged spatially across all RAMP locations within each area which were active during the time period in question. 
Table S2: Statistics for AOD at 470nm in the areas of interest for the entire period of overlap with ground monitoring. Clear Sky indicates percentage of satellite passes for which cloud-free retrievals are available for at least some of the area

15 of interest. Uncertainty indicates median of the estimated AOD uncertainty from the MAIAC output as a percentage of the estimated AOD.

\begin{tabular}{ccccccccc} 
Area & Average & Clear Sky & Uncertainty & \multicolumn{4}{c}{ Percentiles } \\
& & & & $5^{\text {th }}$ & $25^{\text {th }}$ & $50^{\text {th }}$ & $75^{\text {th }}$ & $95^{\text {th }}$ \\
\hline Pittsburgh & 0.28 & $16 \%$ & $11 \%$ & 0.05 & 0.14 & 0.26 & 0.39 & 0.55 \\
Rwanda & 0.36 & $13 \%$ & $6 \%$ & 0.13 & 0.24 & 0.33 & 0.48 & 0.29 \\
Kinshasa & 0.46 & $9 \%$ & $4 \%$ & 0.02 & 0.22 & 0.42 & 0.55 & 1.10 \\
Malawi & 0.25 & $39 \%$ & $9 \%$ & 0.06 & 0.13 & 0.21 & 0.32 & 0.58 \\
Addis Ababa & 0.28 & $18 \%$ & $10 \%$ & 0.09 & 0.17 & 0.26 & 0.36 & 0.54 \\
Kampala & 0.34 & $12 \%$ & $7 \%$ & 0.15 & 0.23 & 0.30 & 0.44 & 0.63
\end{tabular}

Table S3: Statistics for AOD at 550nm in the areas of interest for the entire period of overlap with ground monitoring. Clear Sky indicates percentage of satellite passes for which cloud-free retrievals are available for at least some of the area 20 of interest. Uncertainty indicates median of the estimated AOD uncertainty from the MAIAC output as a percentage of the estimated AOD.

\begin{tabular}{|c|c|c|c|c|c|c|c|c|}
\hline \multirow[t]{2}{*}{ Area } & \multirow[t]{2}{*}{ Average } & \multirow[t]{2}{*}{ Clear Sky } & \multirow[t]{2}{*}{ Uncertainty } & \multicolumn{5}{|c|}{ Percentiles } \\
\hline & & & & $5^{\text {th }}$ & $25^{\text {th }}$ & $50^{\text {th }}$ & $75^{\text {th }}$ & $95^{\text {th }}$ \\
\hline Pittsburgh & 0.20 & $16 \%$ & $17 \%$ & 0.03 & 0.10 & 0.18 & 0.27 & 0.39 \\
\hline Rwanda & 0.26 & $13 \%$ & $9 \%$ & 0.09 & 0.17 & 0.24 & 0.34 & 0.43 \\
\hline Kinshasa & 0.34 & $9 \%$ & $6 \%$ & 0.01 & 0.15 & 0.31 & 0.40 & 0.81 \\
\hline Malawi & 0.18 & $39 \%$ & $13 \%$ & 0.04 & 0.09 & 0.15 & 0.23 & 0.42 \\
\hline Addis Ababa & 0.20 & $18 \%$ & $14 \%$ & 0.07 & 0.12 & 0.19 & 0.26 & 0.39 \\
\hline Kampala & 0.24 & $12 \%$ & $10 \%$ & 0.11 & 0.16 & 0.21 & 0.32 & 0.46 \\
\hline
\end{tabular}

Table S4: Statistics for surface $\mathbf{P M}_{2.5}$ concentration in the areas of interest for the entire period. Values in micrograms per meter cubed.

\begin{tabular}{ccccccc} 
Area & Average & \multicolumn{3}{c}{ Percentiles } \\
& & $5^{\text {th }}$ & $25^{\text {th }}$ & $50^{\text {th }}$ & $75^{\text {th }}$ & $95^{\text {th }}$ \\
\hline Pittsburgh & 9.70 & 3.53 & 5.84 & 8.44 & 12.3 & 20.2 \\
Rwanda & 39.4 & 12.0 & 22.1 & 34.1 & 50.8 & 85.9 \\
Kinshasa & 49.9 & 11.1 & 27.7 & 41.5 & 64.0 & 114 \\
Malawi & 37.6 & 3.54 & 10.1 & 21.1 & 43.5 & 118 \\
Addis Ababa & 20.3 & 6 & 11 & 16 & 25 & 50 \\
Kampala & 60.5 & 25 & 37 & 51 & 75 & 126
\end{tabular}



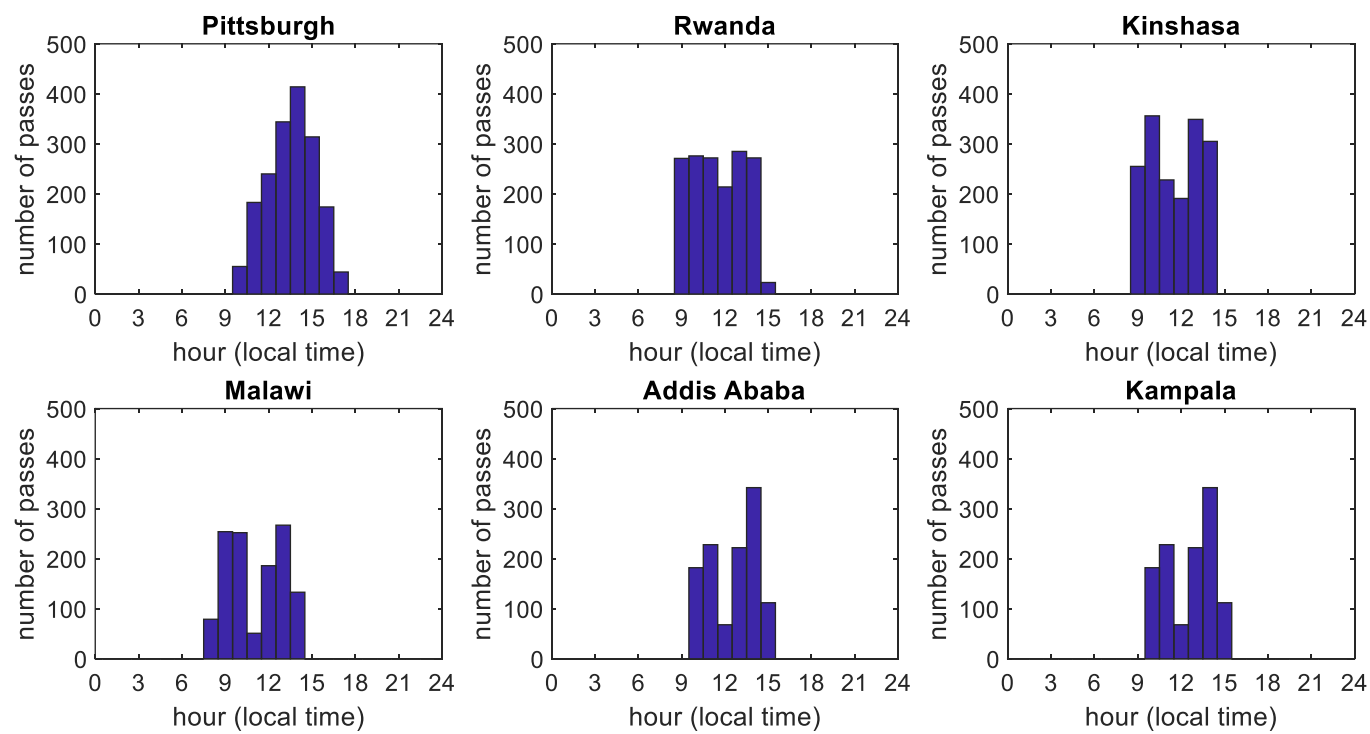

Figure S2: Histograms of satellite overpass times for each area of interest. 

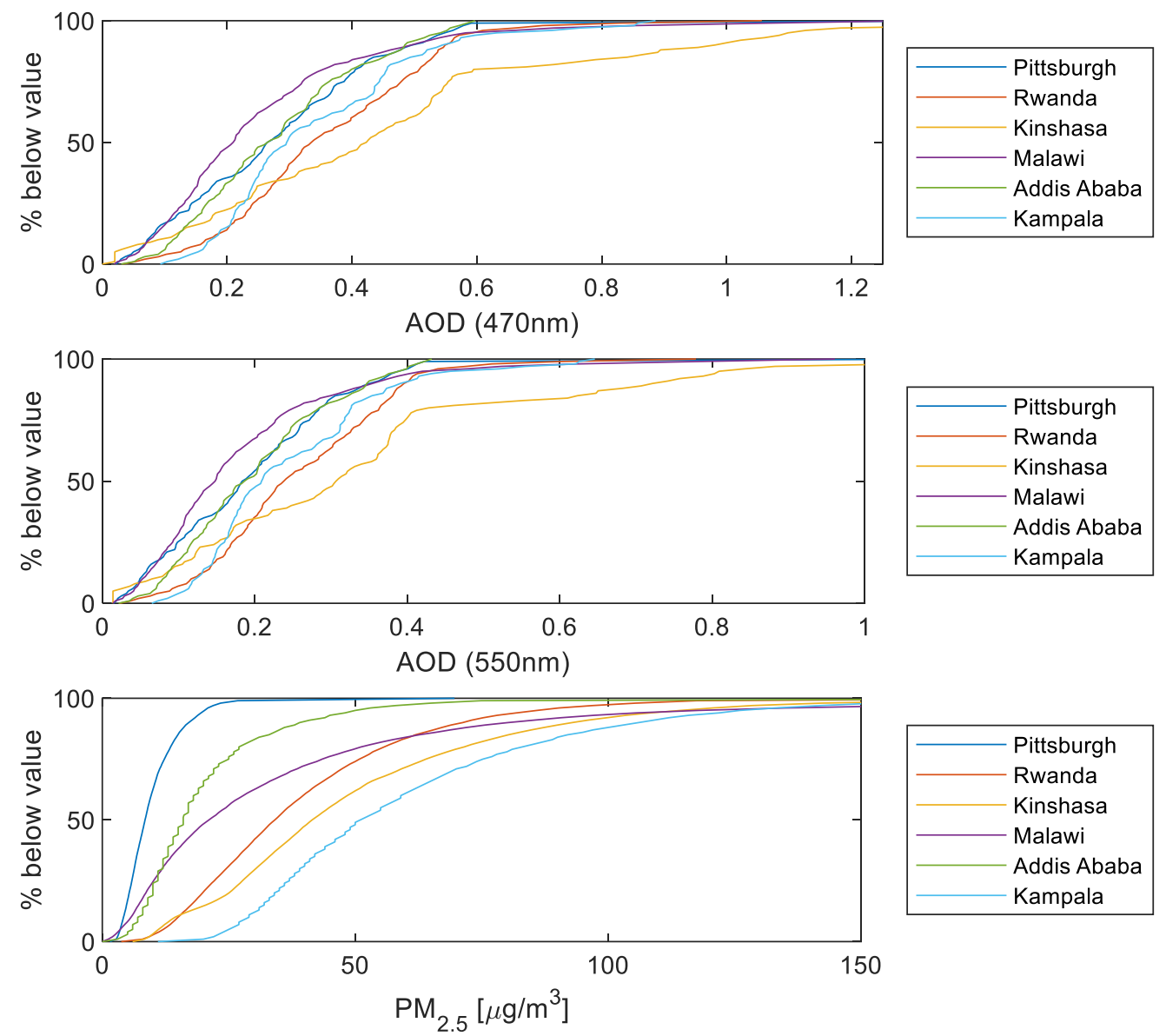

Figure S3: Cumulative Distribution Function plots of AOD and PM2.5 surface concentrations for each of the areas of interest. Values reflect averages across all the ground monitoring site locations within each area. 


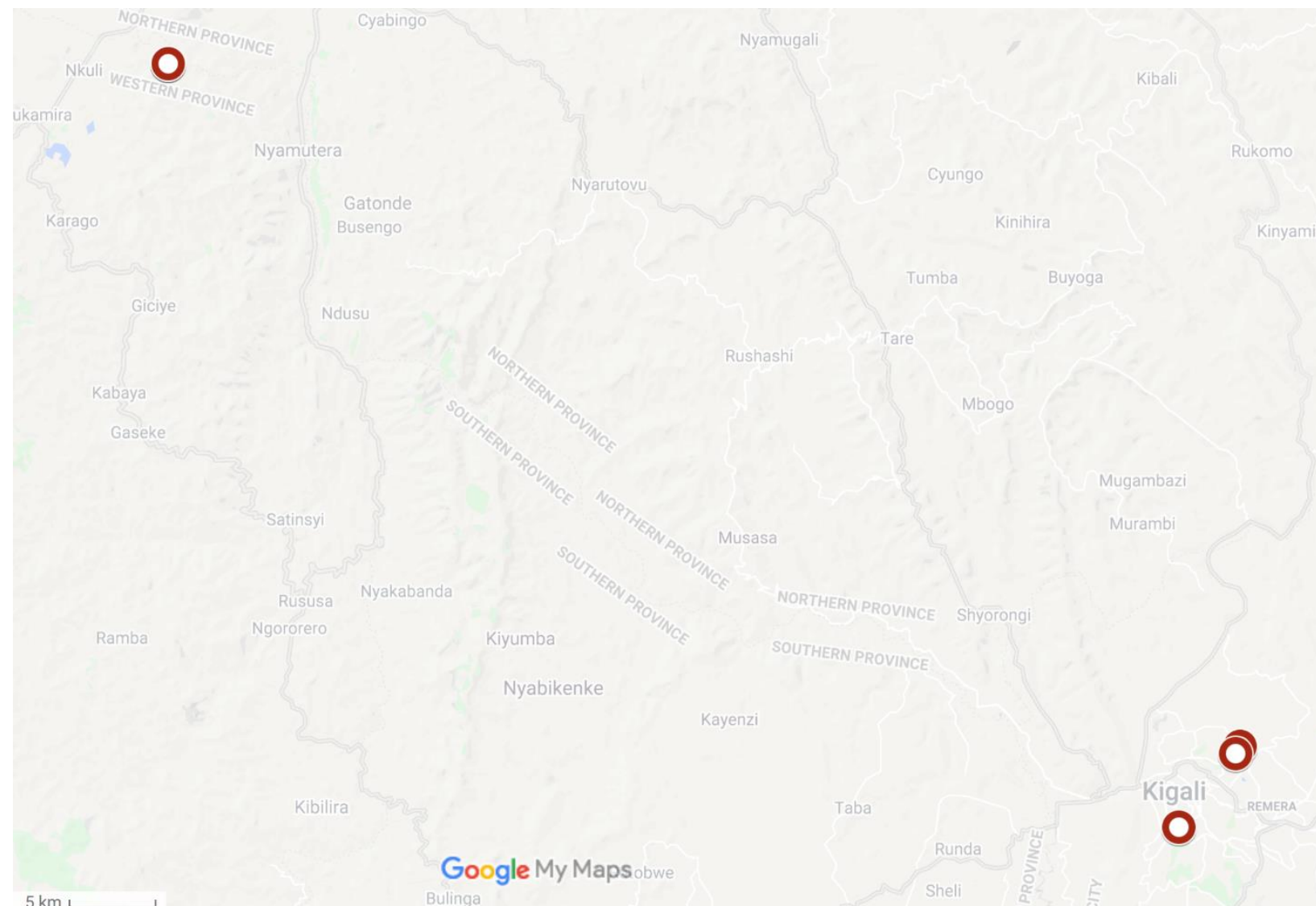

Figure S4: Map of ground sites in the Rwanda area. Red dots represent sites of low-cost sensor deployments, no reference monitors are available in this region. Background map obtained from maps.google.com, map data $\mathbf{2 0 2 0}^{2}$ Google. Note scale in the lower left corner. 


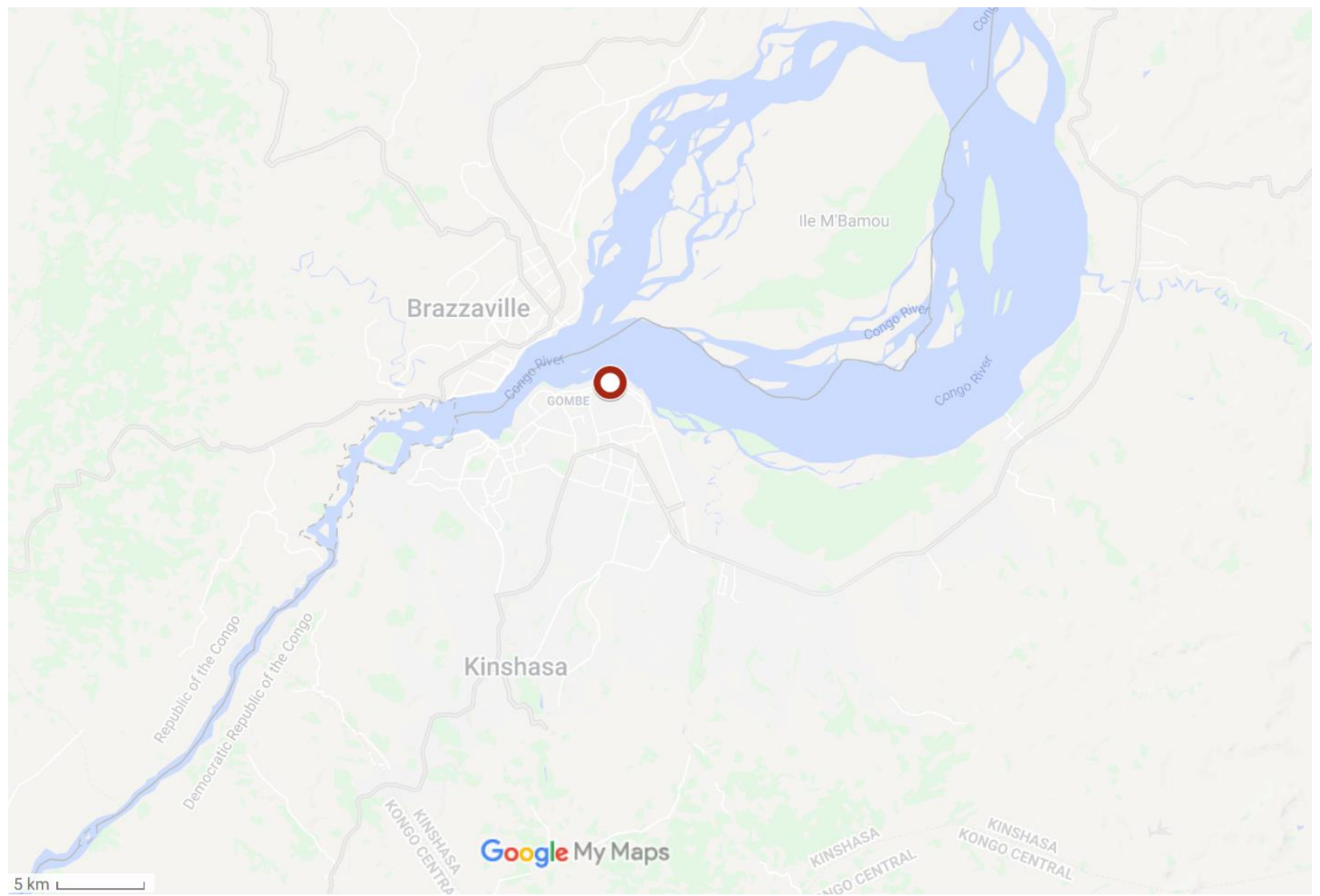

Figure S5: Map of ground sites in the Kinshasa area. Red dots represent sites of low-cost sensor deployments, no reference monitors are available in this region. Background map obtained from maps.google.com, map data @2020 AfriGIS (Pty) Ltd, Google, ORION-ME. Note scale in the lower left corner. 


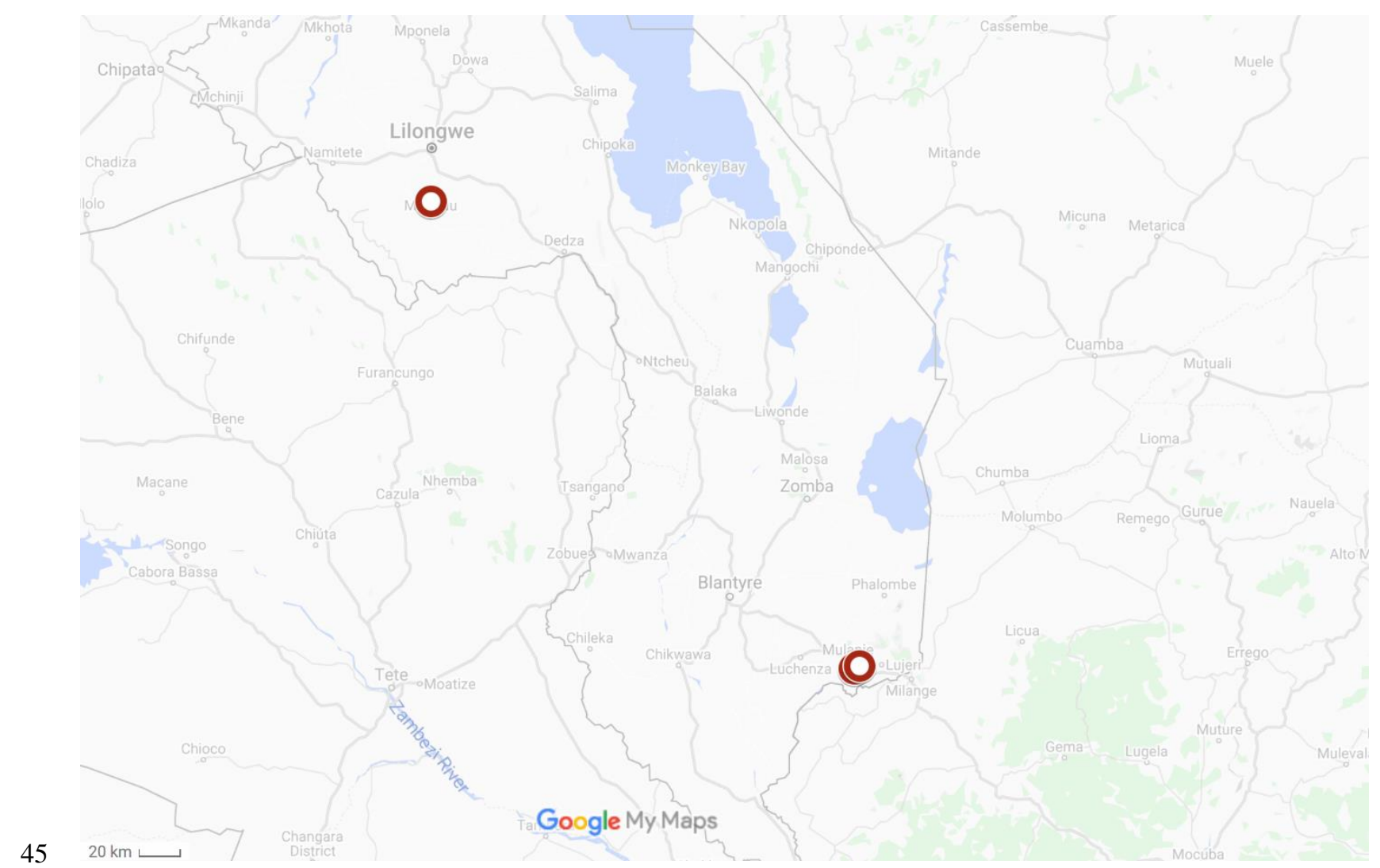

Figure S6: Map of ground sites in the Malawi area. Red dots represent sites of low-cost sensor deployments, no reference monitors are available in this region. Background map obtained from maps.google.com, map data (02020 AfriGIS (Pty) Ltd, Google. Note scale in the lower left corner. 


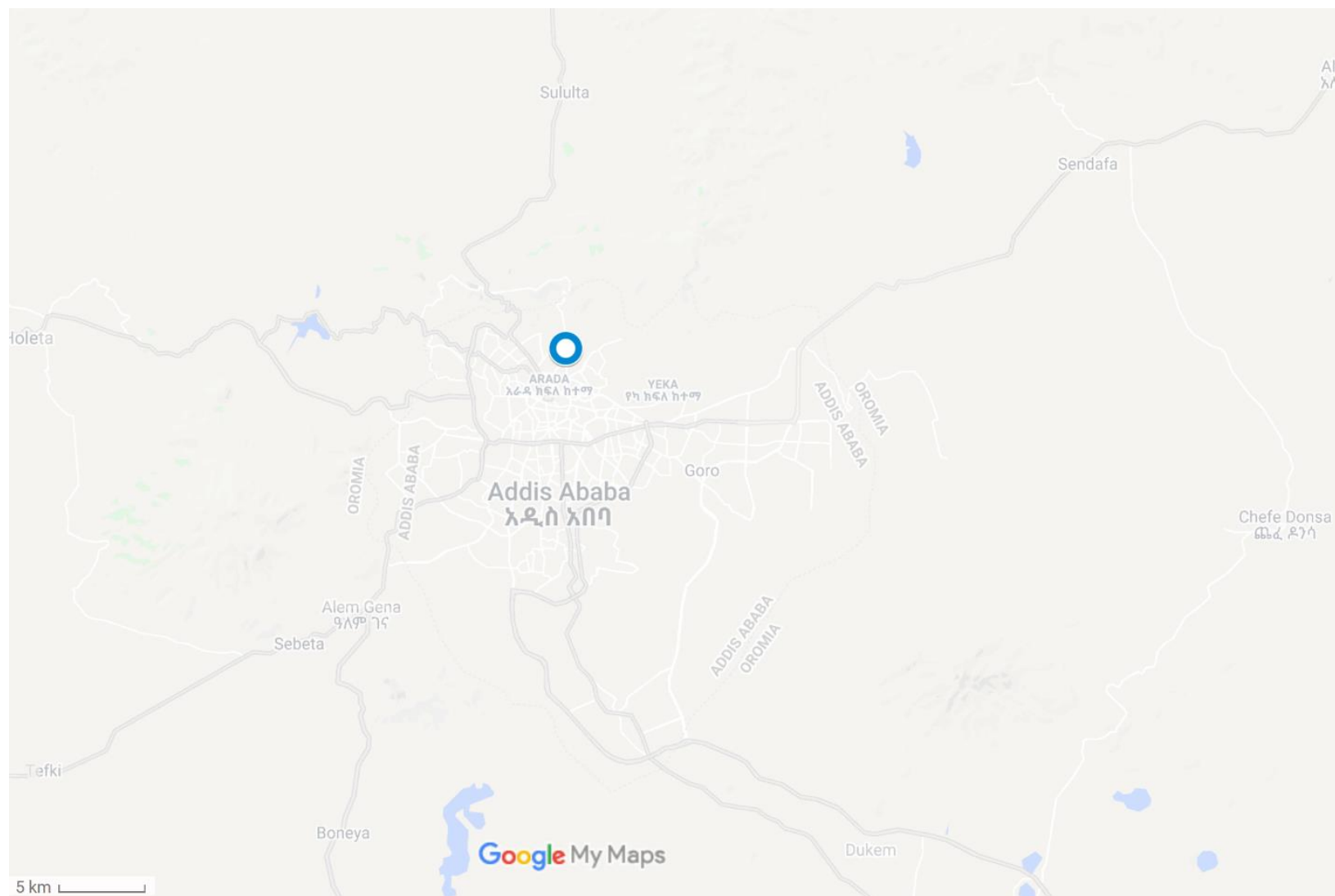

Figure S7: Map of ground sites in the Addis Ababa area. Blue dots represent sites of regulatory-grade monitors used in the analysis; no low-cost sensor data were used for this region. Background map obtained from maps.google.com, map data (C)2020 Google, ORION-ME. Note scale in the lower left corner. 


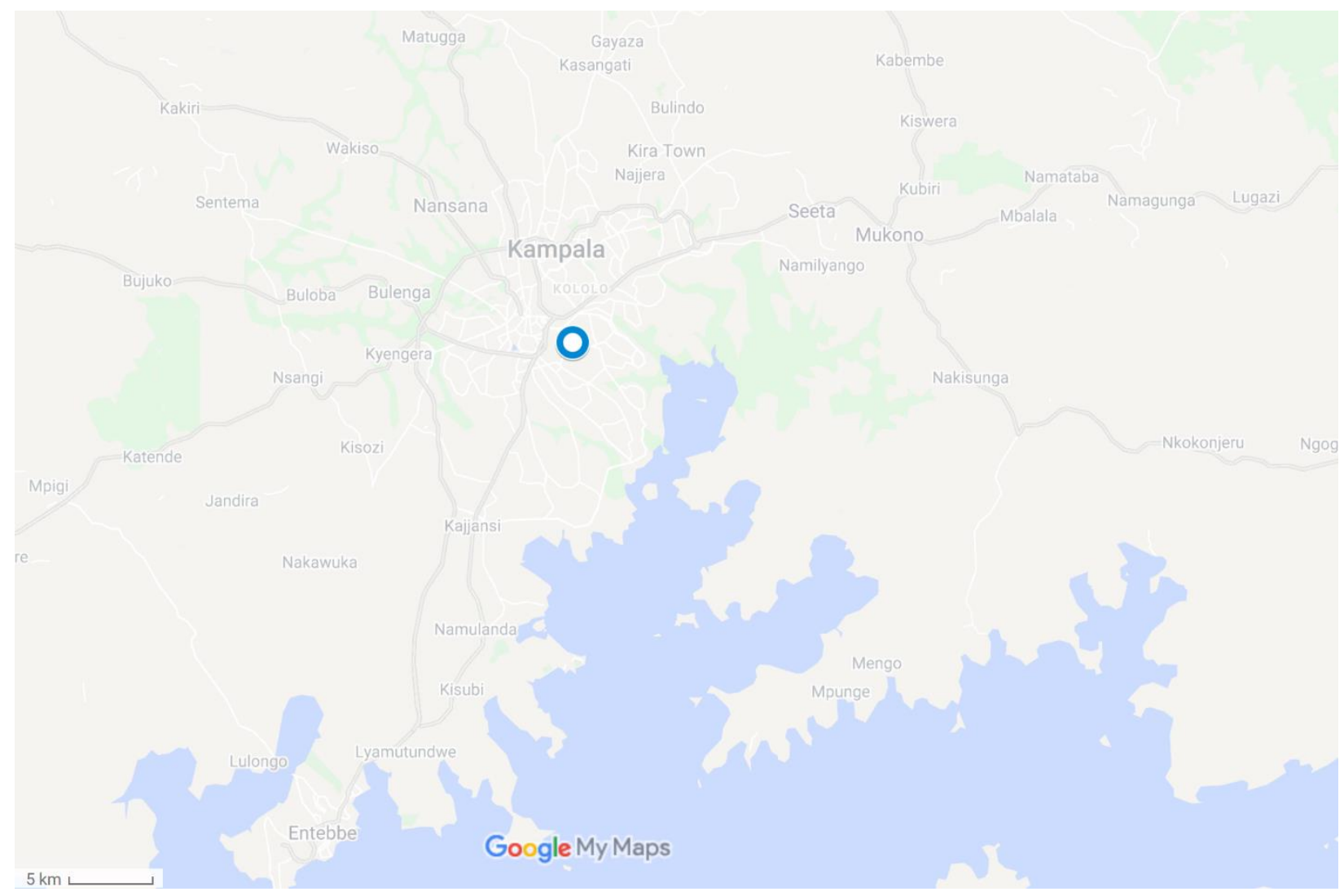

Figure S8: Map of ground sites in the Kampala area. Blue dots represent sites of regulatory-grade monitors used in the analysis; no low-cost sensor data were used for this region. Background map obtained from maps.google.com, map data C)2020 Google. Note scale in the lower left corner.
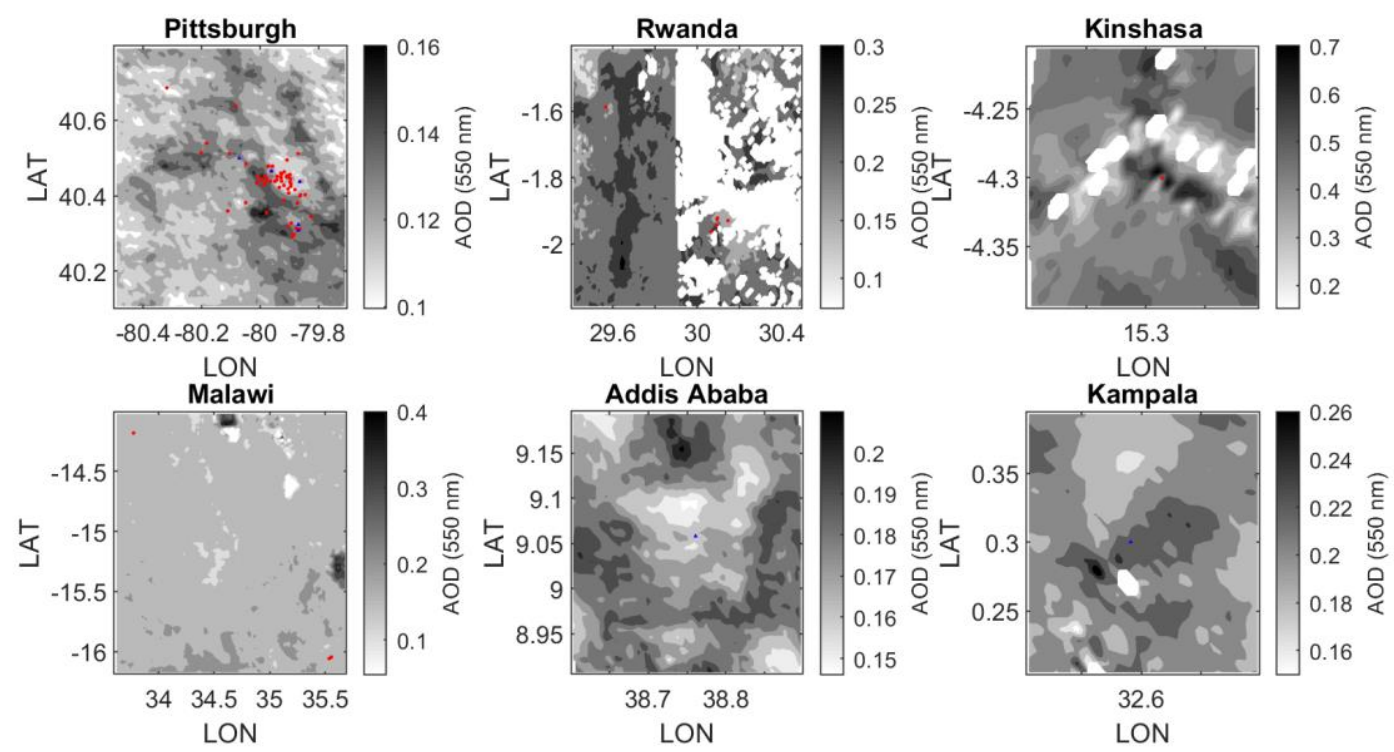

60 Figure S9: Maps depicting the average AOD for each area over the time period considered in the paper. Blue dots represent sites of regulatory-grade monitors used in the analysis, while red dots represent sites of low-cost sensor deployments. 


\section{S2 Methods}

\section{S2.1 Assessment metrics}

Let $\epsilon_{i, t}$ denote the difference (or error) between the estimate of ground-level $\mathrm{PM}_{2.5}$ derived from the satellite data for

65 site $i$ at time $t, \hat{y}_{i, t}$ (which is either $\hat{y}_{i, t \text {,prior }}$ or $\hat{y}_{i, t \text {,post }}$ depending on which approach is being used), and the measurement of surface $\mathrm{PM}_{2.5}$ at the same time from the ground-based monitor, $y_{i, t}$ :

$\epsilon_{i, t}=\hat{y}_{i, t}-y_{i, t}$,

Various statistics are used in this paper to summarize these differences. Among these is the Pearson correlation coefficient, $\mathrm{r}$, which provides a measure of the linearity of the relationship between these quantities. For a site $i$, this

70 is defined as:

$\mathrm{r}_{i}=\frac{\sum_{t \in T_{\mathrm{ap}}}\left(\widehat{\bar{y}}_{i, t}-\overline{\bar{y}}_{i}\right)\left(y_{i, t}-\bar{y}_{i}\right)}{\sqrt{\sum_{t \in T_{\mathrm{ap}}\left(\hat{y}_{i, t}-\bar{y}_{i}\right)^{2}}} \sqrt{\sum_{t \in T_{\mathrm{ap}}\left(y_{i, t}-\bar{y}_{i}\right)^{2}}}}$

where:

$\overline{\bar{y}}_{i}=\frac{1}{n_{\mathrm{ap}, i}} \sum_{t \in T_{\mathrm{ap}}} \hat{\mathrm{y}}_{i, t} \quad \bar{y}_{i}=\frac{1}{n_{\mathrm{ap}, i}} \sum_{t \in T_{\mathrm{ap}}} y_{i, t}$,

and where $n_{\mathrm{ap}, i}$ denotes the number of measures taken at site $i$ during the application period $T_{\mathrm{ap}}$.

75 Another metric used is the mean absolute error (MAE). This measures the average absolute value of the differences during the application period:

$\operatorname{MAE}_{i}=\frac{1}{n_{\mathrm{ap}, i}} \sum_{t \in T_{\mathrm{ap}}}\left|\epsilon_{i, t}\right|$,

To allow for comparison between sites with different average concentrations, a normalized version of the MAE, the Coefficient of Variation of the MAE (CvMAE) is used:

$80 \operatorname{CvMAE}_{i}=\frac{\mathrm{MAE}_{i}}{\bar{y}_{i}}$,

Finally, to assess systematic differences, the bias is used:

$\operatorname{bias}_{i}=\frac{1}{n_{\mathrm{ap}, i}} \sum_{t \in T_{\mathrm{ap}}} \epsilon_{i, t}$

The bias is normalized and presented as the mean-normalized bias (MNB):

$\mathrm{MNB}_{i}=\frac{\text { bias }_{i}}{\bar{y}_{i}}$,

85 S2.2 Comparison of regulatory and low-cost monitors as ground stations to develop conversion factors for AOD

This section provides additional details of the analysis described in Section 2.6.1 and presented in Section 3.1. To assess the utility od the ACHD sites for initialization of conversion factors, four of five sites are used for initialization, with the initialized conversion applied to the AOD, and this converted AOD being compared to surface $\mathrm{PM}_{2.5}$ at the final ACHD site (the one not used for the initialization), as depicted in Fig. S10. This process is repeating, cycling 

of performance metrics, one for each of the ACHD sites used as the performance assessment (application) site.

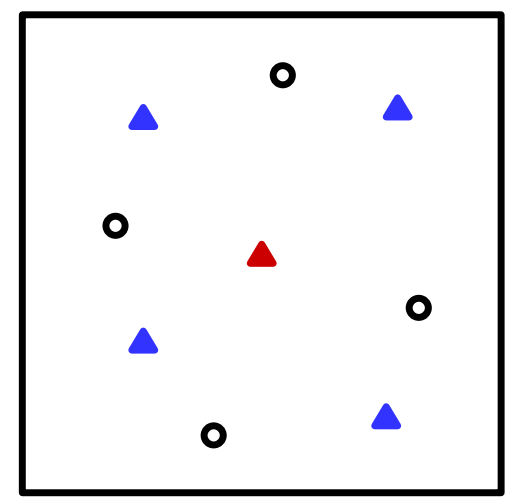

Figure S10: Diagram depicting initialization at all but one ACHD sites (blue triangles) and application to the final site (red 95 triangle). RAMP sites (circles) are not used here.

For the RAMP monitors, all four monitors considered for this analysis (a subset of the full set of RAMP monitor locations) can be used to initialize the conversion factors. There are then applied to the AOD, and performance is evaluated by comparing the AOD-derived surface $\mathrm{PM}_{2.5}$ to measured surface $\mathrm{PM}_{2.5}$ at the five ACHD sites. This is depicted in Fig. S11. The result is a set of five performance metrics, one for each ACHD application site.

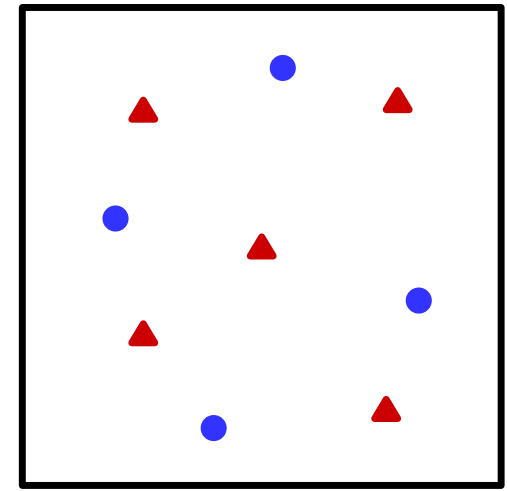

Figure S11: Diagram depicting initialization at all RAMP sites (blue circles) and application to ACHD sites (red triangles).

\section{S2.3 Analysis of AOD conversion factor performance versus number of ground sites}

This section provides additional details of the analysis described in Section 2.6.2 and presented in Section 3.2. To assess the performance of using varying numbers of ACHD sites as initialization sites, We begin by withholding one of the ACHD sites to use as an application site, and from the remaining ACHD sites, select one site at random to serve as the initialization site. This is depicted in Fig. S12 for ten random selections of the initialization site. Note that due to the limited number of ACHD site, the same initialization site will be selected multiple times over the course of randomization. The average of the performance metrics assessed at the application site is then taken across these ten

110 iterations. This process is then repeated, using each of the five ACHD sites as the application site. The result is a set of five performance metrics, one for each ACHD site, where each performance metric is an average of the metrics assessed across the ten random iterations where that site was the application site. 

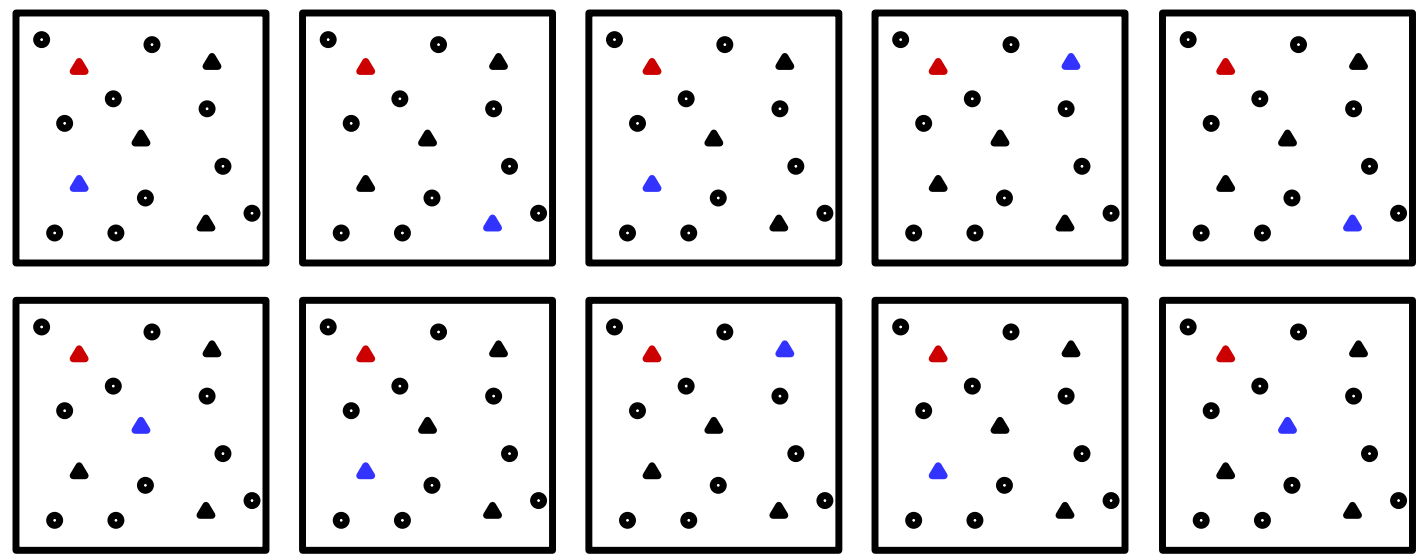

Figure S12: Diagram with ten examples of randomized selection of a single initialization site from among the ACHD sites (blue triangle) with a fixed ACHD application site (red triangle). RAMP sites (circles) are not used here.

This process is then repeated for randomized sets of two, three (depicted in Fig. S13), and four initialization sites chosen from among the ACHD sites. In all cases, the five ACHD sites are rotated through with one ACHD site left aside for application. In the case of four ACHD initialization sites, there is no randomization involved, as all four of the remaining sites must be included. The overall result of this process is a set of twenty performance metrics, that is, for each of the four different numbers of initialization sites (one, two, three, and four) there is an assessed performance metric for each of the five ACHD sites used for application (with each of these assessed metrics being the average across the ten random iterations which were attempted for that particular combination of application site and number of initialization sites).
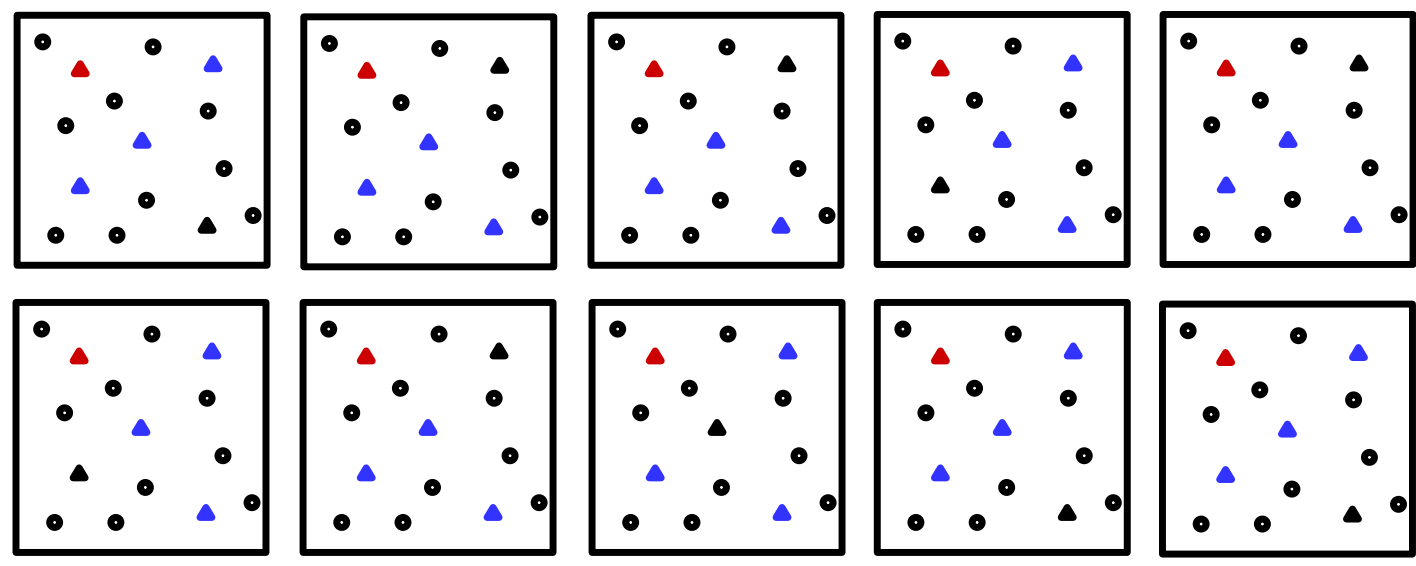

Figure S13: Diagram with ten examples of a randomized selection of three initialization sites from among the ACHD sites (blue triangles) with a fixed ACHD application site (red triangle). RAMP sites (circles) are not used here.

130 For the RAMP sensors, all ACHD sites can be used as application sites. Therefore, for each potential number of RAMP initialization sites, there are ten random iterations, where that number of RAMP sites are randomly selected and used as initialization sites, and the resulting conversion factors are applied to AOD data and performance is assessed at each of the ACHD sites. This process is depicted for one (Fig. S14), three (Fig. S15), and seven (Fig. S16) initialization sites. The result is, for each number of initialization sites, a set of five performance metrics, one for each 

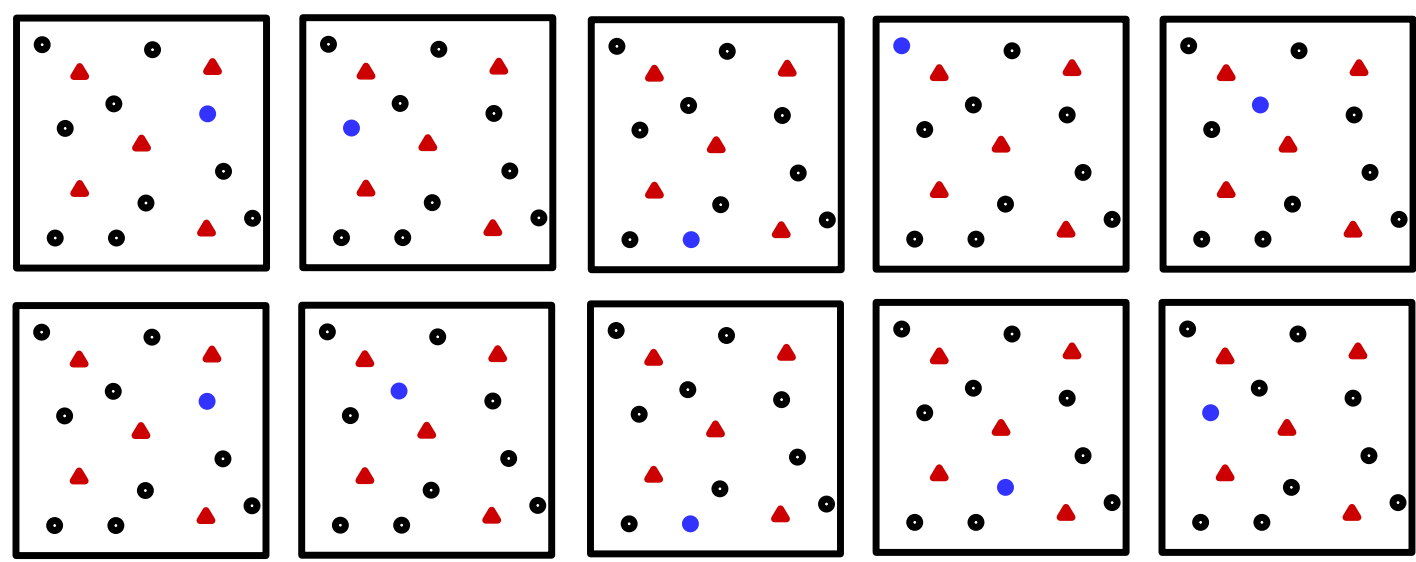

Figure S14: Diagram with ten examples of a randomized selection of one initialization site from among the RAMP sites (blue circles) and application to all ACHD sites (red triangles).
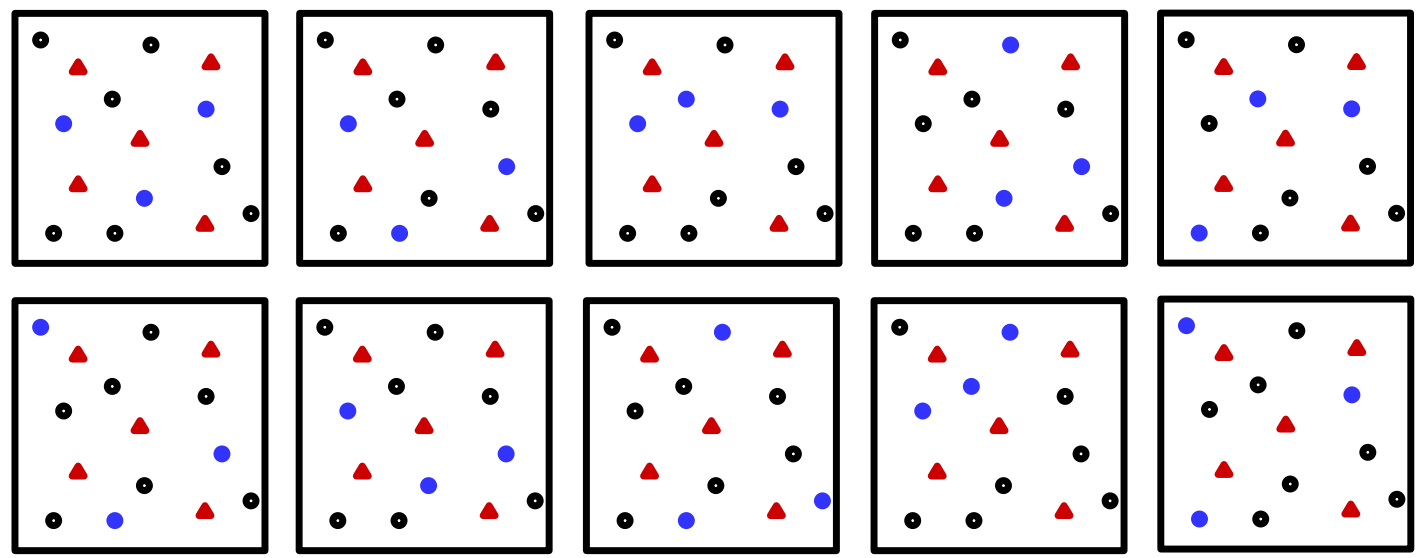

Figure S15: Diagram with ten examples of a randomized selection of one initialization site from among the RAMP sites (blue circles) and application to all ACHD sites (red triangles).
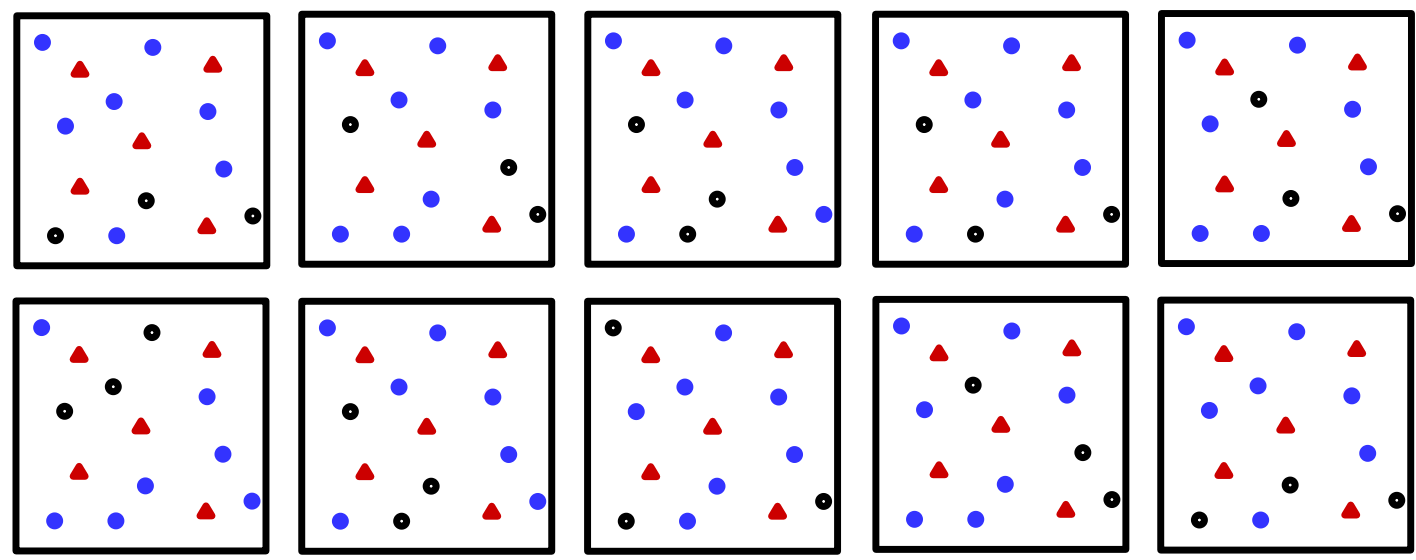

Figure S16: Diagram with ten examples of a randomized selection of one initialization site from among the RAMP sites (blue circles) and application to all ACHD sites (red triangles). 


\section{S2.4 Comparison of converted AOD and nearest ground monitors as proxies for surface $\mathbf{P M}_{2.5}$}

This section provides additional details of the analysis described in Section 2.6.3 and presented in Sections 3.3 and 3.4. Here, the RAMP sites are used for both initialization and application. Each RAMP site it held out as an application site, with the rest of the RAMP sites being used for initialization. The RAMP sites are cycled through in this manner. The result is a set of performance metrics for each RAMP site, representing the performance of the AOD conversion

155 as applied to that site when all other sites were used for initialization. In the case of the nearest monitor interpolation method, the initialization location which is closest to the application location in each case is used (as depicted in Fig. S17). Thus, a corresponding set of performance metrics are generated for this method.

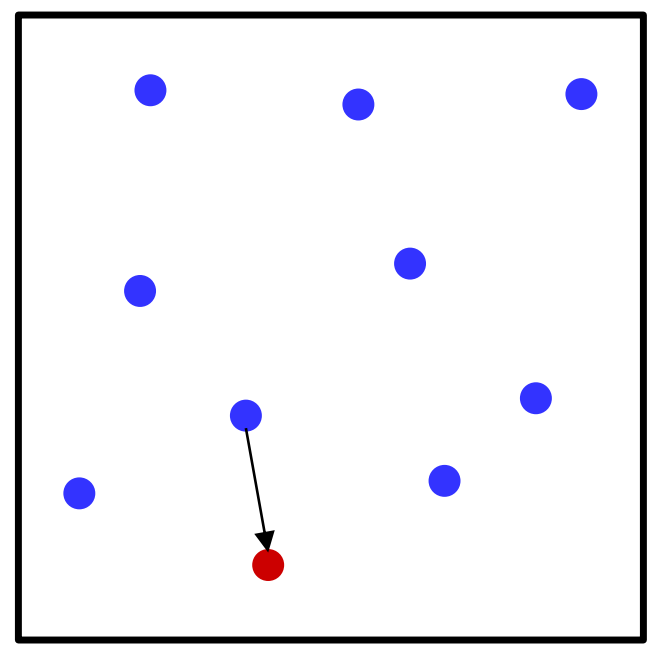

160 Figure S17: Diagram depicting nearest monitor interpolation method. The red circle is the application site, and the blue circles represent the remaining RAMP sites which were used for initialization of the AOD conversion. 


\section{S3 Results}

\section{S3.1 Conversion Parameters and Results}

Table S5: Coefficients for conversion factors developed by initialization at ACHD sites in the Pittsburgh area. Coefficients for yearly application, for seasonal application, and for monthly application (with the month listed being the initialization month) are listed. These represent the prior coefficients developed during the initialization, i.e. the elements of $\beta_{\text {in }}$.

\begin{tabular}{|l|c|c|c|c|c|}
\hline & & \multicolumn{2}{|c|}{ With AOD at 550 nm } & \multicolumn{2}{c|}{ With AOD at 470 nm } \\
\hline & & $A O D$ & Constant & $A O D$ & Constant \\
\hline ACHD Yearly & & 11.3 & 8.14 & 8.99 & 7.93 \\
\hline & & & & & \\
\hline ACHD Seasonal & Winter & 41.7 & 3.68 & 28.8 & 3.67 \\
\hline & Spring & 45.1 & 2.37 & 31.7 & 2.30 \\
\hline & Sumer & -1.11 & 12.2 & -0.41 & 12.1 \\
\hline & Fall & 30.0 & 6.08 & 21.1 & 6.02 \\
\hline & & & & & \\
\hline ACHD Monthly & Jan & 184 & -4.60 & 127 & -4.69 \\
\hline & Feb & -5.71 & 4.84 & -4.15 & 4.85 \\
\hline & Mar & 15.4 & 3.46 & 10.8 & 3.44 \\
\hline & Apr & 51.2 & 0.52 & 36.1 & 0.40 \\
\hline & May & 26.3 & 7.60 & 18.7 & 7.50 \\
\hline & Jun & 24.2 & 8.34 & 17.2 & 8.25 \\
\hline & Jul & 28.0 & 7.58 & 20.0 & 7.49 \\
\hline & Aug & -11.4 & 15.5 & -8.82 & 15.8 \\
\hline & Sep & 7.71 & 10.0 & 5.64 & 9.95 \\
\hline & Oct & 40.9 & 3.98 & 28.6 & 3.93 \\
\hline & Nov & 38.0 & 6.20 & 26.5 & 6.16 \\
\hline
\end{tabular}

Table S6: Coefficients for conversion factors developed by initialization at RAMP sites in the Pittsburgh area. Coefficients for yearly application, for seasonal application, and for monthly application (with the month listed being the initialization month) are listed. These represent the prior coefficients developed during the initialization, i.e. the elements of $\beta_{\text {in }}$.

\begin{tabular}{|l|c|c|c|c|c|}
\hline & & \multicolumn{2}{|c|}{ With AOD at 550 nm } & \multicolumn{2}{c|}{ With AOD at 470 nm } \\
\hline & & $A O D$ & Constant & $A O D$ & Constant \\
\hline RAMP Yearly & & 11.0 & 6.74 & 8.57 & 6.56 \\
\hline & & & & & \\
\hline RAMP Seasonal & Winter & -2.01 & 5.52 & -1.34 & 5.52 \\
& Spring & 29.8 & 3.56 & 21.0 & 3.50 \\
\hline & Sumer & 5.22 & 8.99 & 4.38 & 8.79 \\
\hline & Fall & 7.44 & 6.62 & 5.23 & 6.60 \\
\hline & & & & & \\
\hline RAMP Monthly & Jan & 28.1 & 4.43 & 19.2 & 4.43 \\
\hline & Feb & -10.8 & 5.43 & -7.51 & 5.44 \\
\hline & Mar & 10.1 & 3.48 & 7.10 & 3.47 \\
\hline & Apr & 38.9 & 2.85 & 27.3 & 2.78 \\
\hline & May & 19.9 & 6.60 & 14.2 & 6.51 \\
\hline & Jun & 31.3 & 3.83 & 22.0 & 3.76 \\
\hline & Jul & 37.5 & 4.24 & 26.7 & 4.12 \\
\hline & Aug & -7.35 & 14.1 & -5.61 & 14.3 \\
\hline & Sep & 5.90 & 7.90 & 4.19 & 7.88 \\
\hline & Oct & 6.63 & 5.31 & 4.64 & 5.30 \\
\hline & Nov & 7.59 & 7.49 & 5.23 & 7.49 \\
\hline
\end{tabular}


Table S7: Coefficients for conversion factors developed by initialization at RAMP sites in the Rwanda area. Coefficients for application to the full analysis period, for seasonal application, and for monthly application (with the month listed being the initialization month) are listed. These represent the prior coefficients developed during the initialization, i.e. the elements of $\beta_{\text {in }}$.

\begin{tabular}{|c|c|c|c|c|c|}
\hline & & \multicolumn{2}{|c|}{ With AOD at $550 \mathrm{~nm}$} & \multicolumn{2}{|c|}{ With AOD at $470 \mathrm{~nm}$} \\
\hline & & $A O D$ & Constant & $A O D$ & Constant \\
\hline RAMP Full Period & & 106 & 22.7 & 76.6 & 22.3 \\
\hline \multirow[t]{5}{*}{ RAMP Seasonal } & Wet Season 1 & & & & \\
\hline & Dry Season 1 & 152 & 24.5 & 110 & 23.9 \\
\hline & Wet Season 2 & 8.62 & 31.6 & 5.7 & 31.7 \\
\hline & Dry Season 2 & 95.4 & 26.9 & 72.6 & 24.8 \\
\hline & Wet Season 3 & 33.8 & 22.8 & 24.5 & 22.6 \\
\hline \multirow[t]{10}{*}{ RAMP Monthly } & Jul 2018 & 107 & 42.7 & 77.7 & 42.1 \\
\hline & Aug 2018 & 145 & 20.3 & 104 & 20.0 \\
\hline & Sep 2018 & 2.08 & 41.1 & 1.36 & 41.1 \\
\hline & Oct 2018 & -51.9 & 39.7 & -36.6 & 39.7 \\
\hline & Nov 2018 & 87.8 & 2.83 & 63.4 & 2.47 \\
\hline & Dec 2018 & 46.4 & 26.9 & 33.2 & 26.8 \\
\hline & Jan 2019 & -197 & 166 & -146 & 168 \\
\hline & Feb 2019 & 167 & -0.8 & 121 & -1.37 \\
\hline & Mar 2019 & -22.8 & 39.0 & -16.9 & 39.2 \\
\hline & Apr 2019 & -1413 & 529 & -25.0 & 93.6 \\
\hline
\end{tabular}


Table S8: Numerical values presented in Fig. 8.

\begin{tabular}{|c|c|c|c|c|c|}
\hline (a) & \multicolumn{5}{|c|}{ Pittsburgh, $r$} \\
\hline Win. & 0.31 & 0.31 & 0.31 & 0.31 & \\
\hline Spt. & 0.65 & 0.65 & 0.65 & 0.65 & \\
\hline Sum. & 0.14 & 0.14 & 0.14 & 0.14 & \\
\hline Fall. & 0.52 & 0.52 & 0.52 & 0.52 & \\
\hline & Win. & Spr. & Sum. & Fall & \\
\hline (b) & \multicolumn{5}{|c|}{ Pittsburgh, CvMAE } \\
\hline Win. & 0.30 & 0.31 & 0.79 & 0.37 & \\
\hline Spt. & 0.40 & 0.31 & 0.57 & 0.35 & \\
\hline Sum. & 0.46 & 0.42 & 0.43 & 0.42 & \\
\hline Fall. & 0.34 & 0.31 & 0.41 & 0.30 & \\
\hline & Win. & Spr. & Sum. & Fall & \\
\hline (c) & \multicolumn{5}{|c|}{ Pittsburgh, mean-normalized bias } \\
\hline Win. & 0.078 & 0.068 & 0.79 & 0.24 & \\
\hline Spt. & -0.13 & 0.047 & 0.41 & 0.13 & \\
\hline Sum. & -0.34 & -0.026 & 0.0027 & 0.0055 & \\
\hline Fall. & -0.24 & -0.087 & 0.23 & -0.0060 & \\
\hline & Win. & Spr. & Sum. & Fall & \\
\hline (d) & \multicolumn{5}{|c|}{ Rwanda, $\mathrm{r}$} \\
\hline WS1 & 0.078 & 0.078 & 0.078 & 0.078 & 0.078 \\
\hline DS1 & 0.46 & 0.40 & 0.46 & 0.019 & 0.019 \\
\hline WS2 & 0.33 & 0.073 & 0.33 & 0.38 & 0.38 \\
\hline DS2 & 0.33 & 0.33 & 0.33 & N/A & N/A \\
\hline WS3 & 0.16 & 0.16 & 0.16 & N/A & N/A \\
\hline & WS1 & DS1 & WS2 & DS2 & WS3 \\
\hline (e) & \multicolumn{5}{|c|}{ Rwanda, CvMAE } \\
\hline WS1 & 0.28 & 1.20 & 0.22 & 0.84 & 0.26 \\
\hline DS1 & 0.50 & 0.30 & 0.53 & 0.27 & 0.48 \\
\hline WS2 & 0.33 & 0.81 & 0.35 & 1.10 & 0.50 \\
\hline DS2 & 0.53 & 0.46 & 0.52 & N/A & N/A \\
\hline WS3 & 0.40 & 1.00 & 0.39 & N/A & N/A \\
\hline & WS1 & DS1 & WS2 & DS2 & WS3 \\
\hline (f) & \multicolumn{5}{|c|}{ Rwanda, mean-normalized bias } \\
\hline WS1 & 0.21 & 1.20 & 0.059 & 0.79 & 0.072 \\
\hline DS1 & -0.50 & 0.0089 & -0.53 & -0.13 & -0.48 \\
\hline WS2 & -0.002 & 0.69 & -0.071 & 1.0 & 0.32 \\
\hline DS2 & -0.48 & 0.15 & -0.48 & N/A & N/A \\
\hline WS3 & -0.0002 & 0.95 & -0.059 & N/A & N/A \\
\hline & WS1 & DS1 & WS2 & DS2 & WS3 \\
\hline
\end{tabular}




\section{S3.2 Results for AOD at 470nm}

(a)

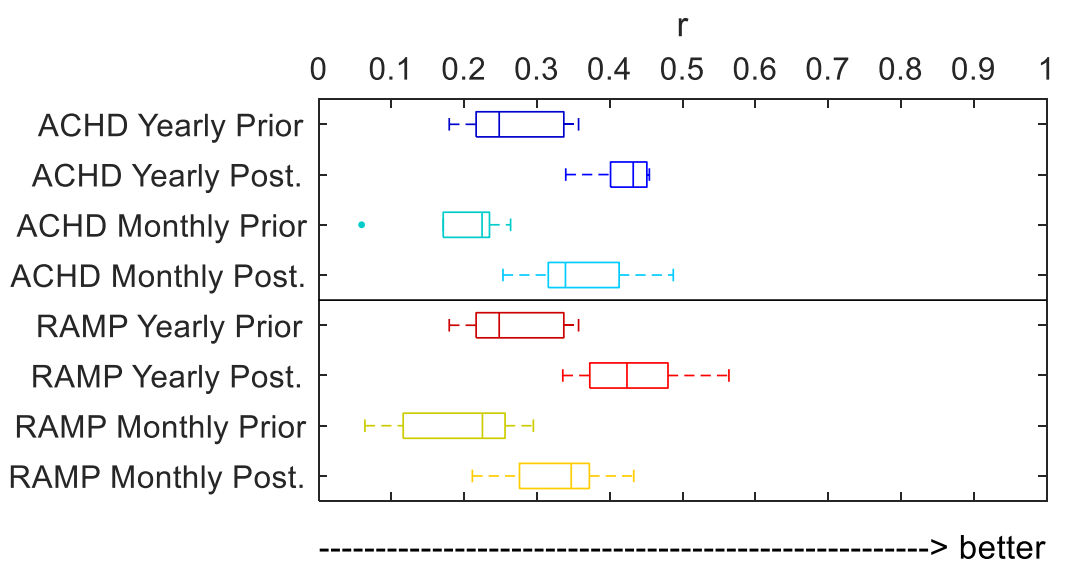

(b)

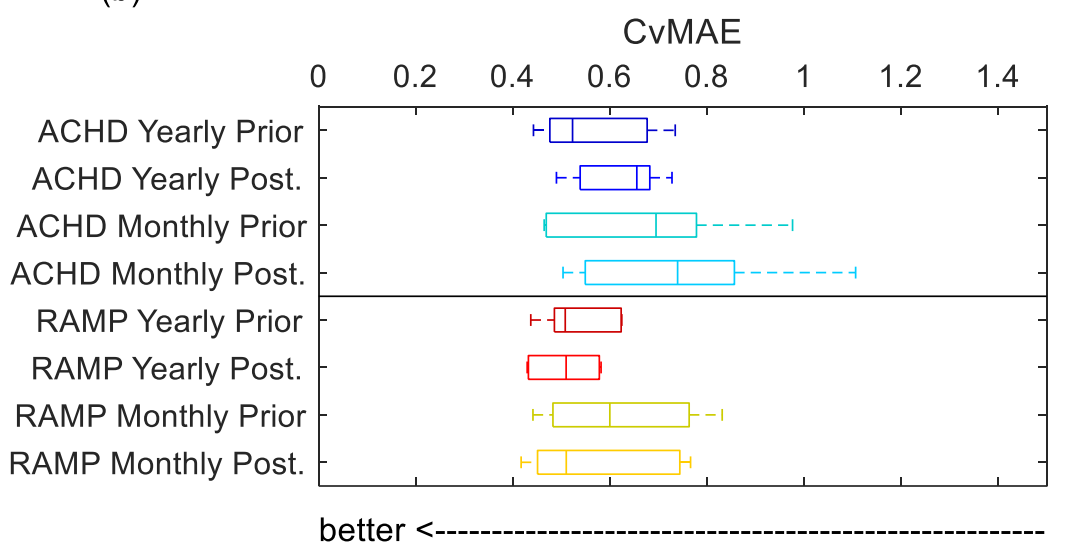

(c)

mean normalized bias

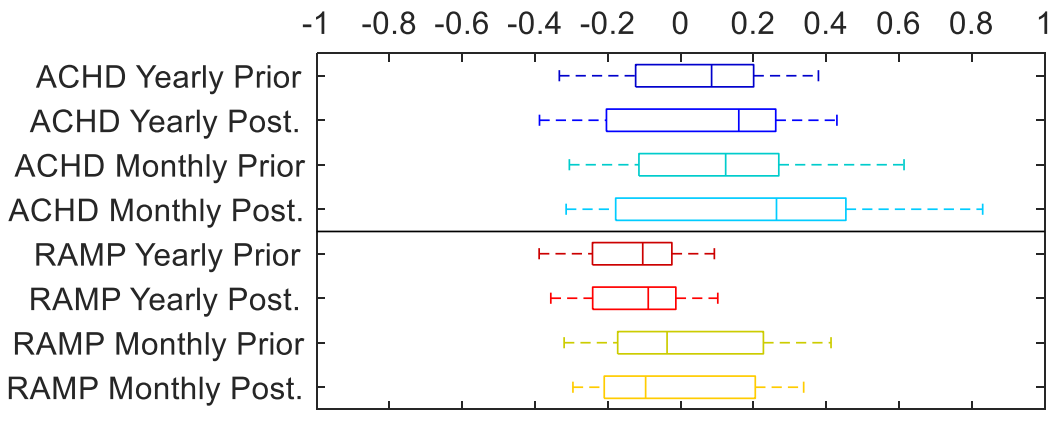

180

better

Figure S18: Results corresponding to Fig. 3 for AOD at $470 \mathrm{~nm}$. 


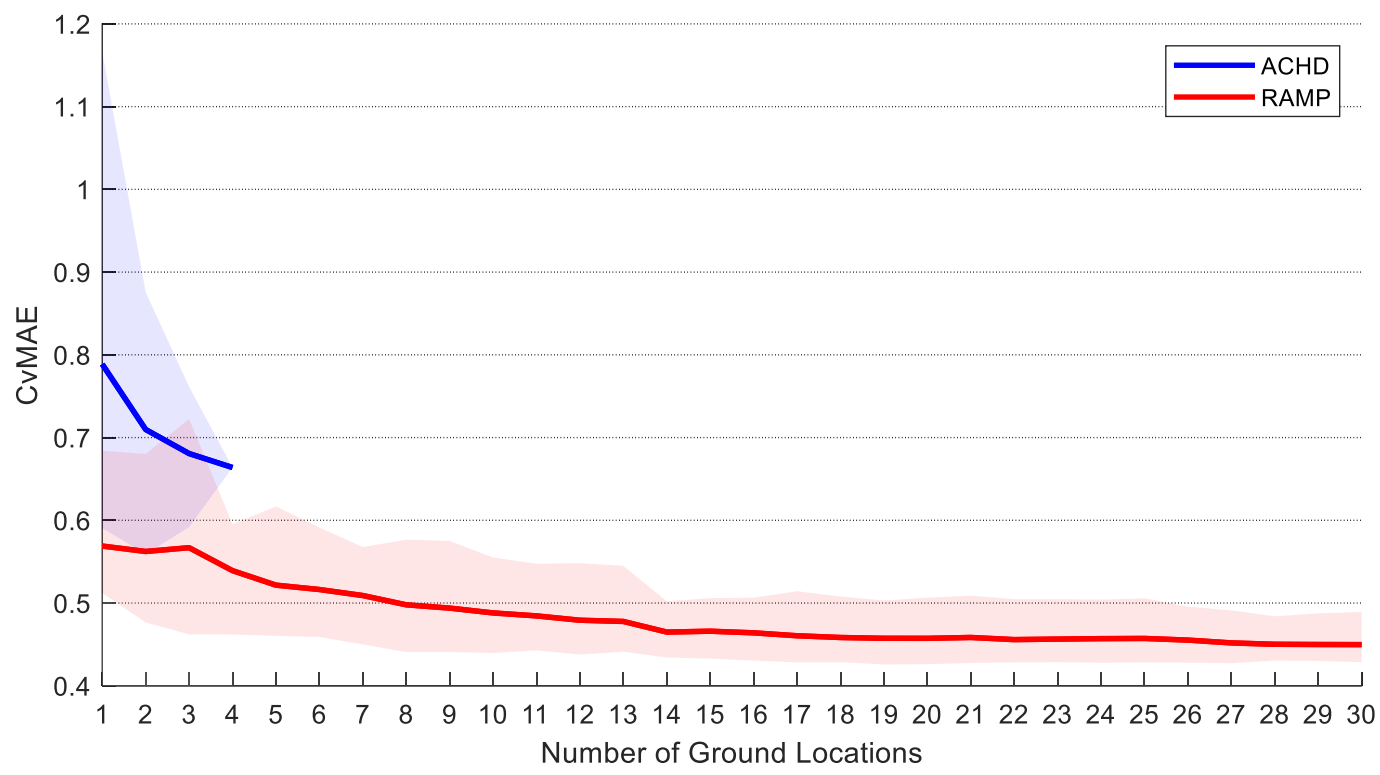

Figure S19: Results corresponding to Fig. 4 for AOD at $470 \mathrm{~nm}$.

\section{Pittsburgh}

(a)

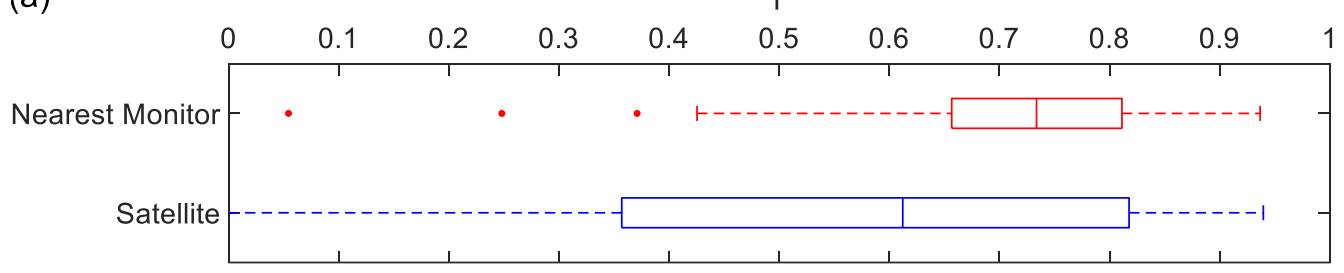

(b) CvMAE

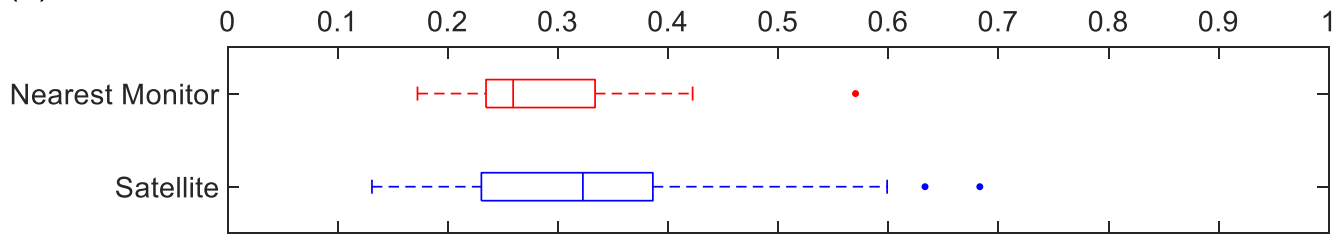

(c)

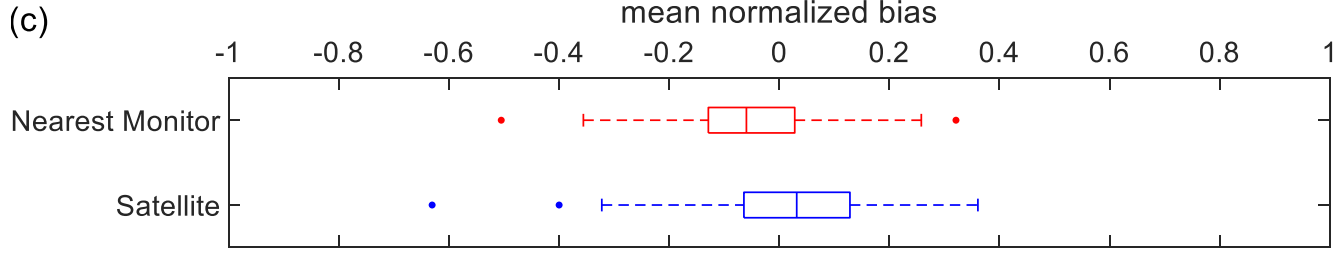

Figure S20: Results corresponding to Fig. 5 for AOD at $470 \mathrm{~nm}$. 
(a)

\section{Rwanda}

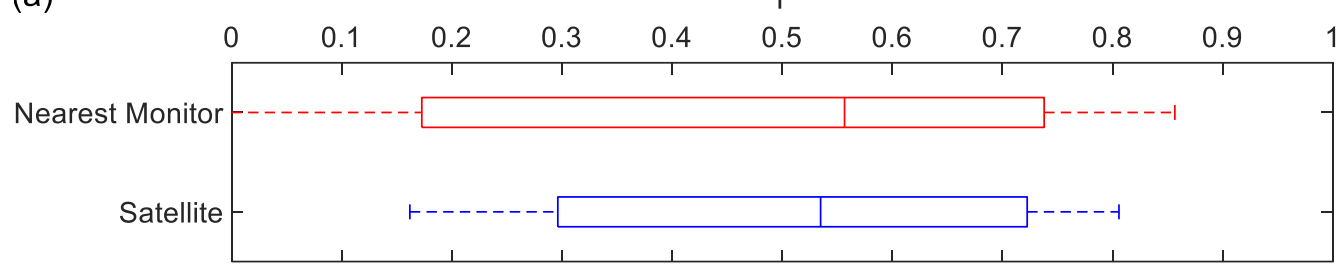

(b)

CVMAE

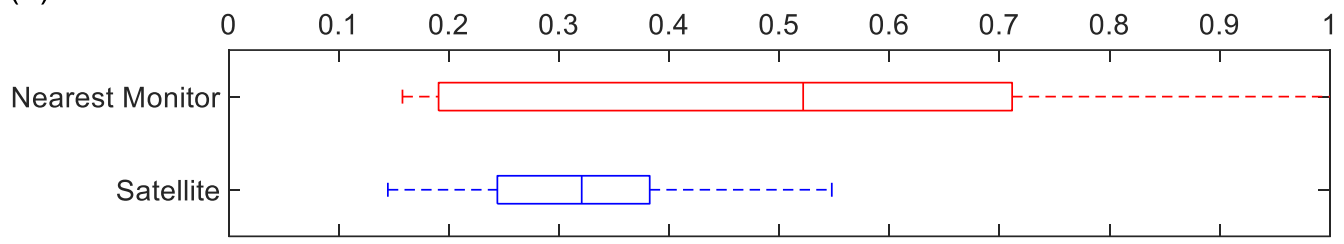

(c)

\begin{tabular}{|c|c|c|c|c|c|c|c|c|c|}
\hline-1 & -0.8 & -0.6 & -0.4 & -0.2 & 0 & 0.2 & 0.4 & 0.6 & 0.8 \\
\hline Nearest Monitor & & & & & $\perp$ & & & & \\
\hline Satellite & & & & & & & & & \\
\hline
\end{tabular}

190 Figure S21: Results corresponding to Fig. 6 for AOD at $470 \mathbf{~ n m . ~}$

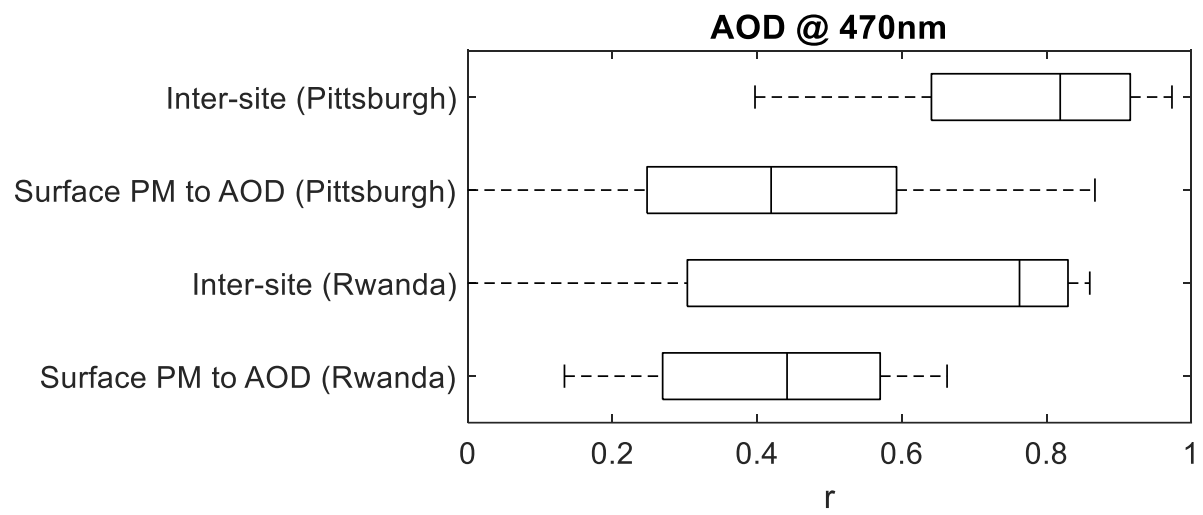

Figure S22: Results corresponding to Fig. 7 for AOD at $470 \mathrm{~nm}$. 
(a)

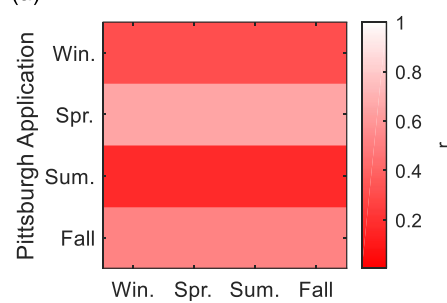

(d)

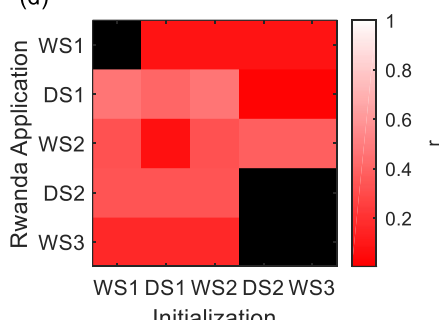

(b)

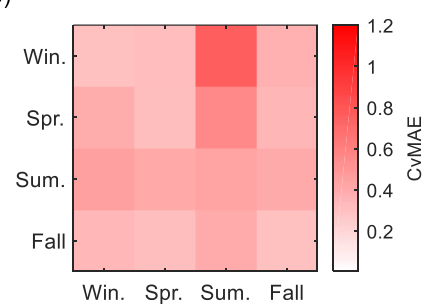

(e)

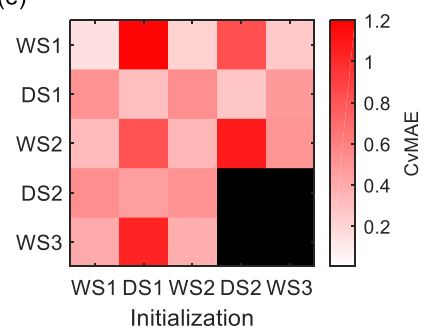

(c)

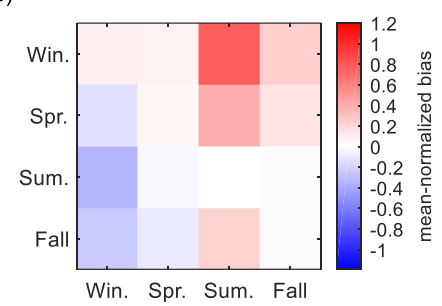

(f)

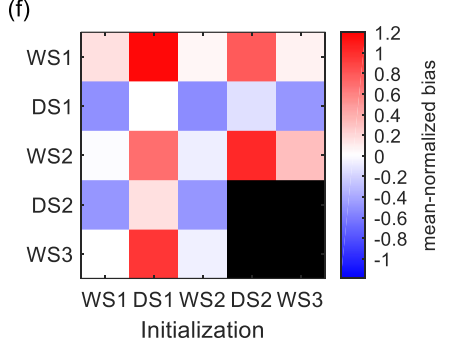

Figure S23: Results corresponding to Fig. 8 for AOD at $470 \mathrm{~nm}$. 
Table S9: Numerical values presented in Fig. S23.

\begin{tabular}{|c|c|c|c|c|c|}
\hline (a) & \multicolumn{5}{|c|}{ Pittsburgh, $r$} \\
\hline Win. & 0.31 & 0.31 & 0.31 & 0.31 & \\
\hline Spt. & 0.65 & 0.65 & 0.65 & 0.65 & \\
\hline Sum. & 0.17 & 0.17 & 0.17 & 0.17 & \\
\hline Fall. & 0.52 & 0.52 & 0.52 & 0.52 & \\
\hline & Win. & Spr. & Sum. & Fall & \\
\hline (b) & \multicolumn{5}{|c|}{ Pittsburgh, CvMAE } \\
\hline Win. & 0.30 & 0.31 & 0.75 & 0.38 & \\
\hline Spt. & 0.40 & 0.31 & 0.56 & 0.35 & \\
\hline Sum. & 0.45 & 0.41 & 0.43 & 0.41 & \\
\hline Fall. & 0.34 & 0.31 & 0.40 & 0.30 & \\
\hline & Win. & Spr. & Sum. & Fall & \\
\hline (c) & \multicolumn{5}{|c|}{ Pittsburgh, mean-normalized bias } \\
\hline Win. & 0.078 & 0.066 & 0.76 & 0.24 & \\
\hline Spt. & -0.13 & 0.048 & 0.40 & 0.13 & \\
\hline Sum. & -0.34 & -0.028 & 0.0041 & -0.0060 & \\
\hline Fall. & -0.24 & -0.087 & 0.22 & -0.0060 & \\
\hline & Win. & Spr. & Sum. & Fall & \\
\hline (d) & \multicolumn{5}{|c|}{ Rwanda, $\mathrm{r}$} \\
\hline WS1 & N/A & .079 & 0.079 & 0.079 & 0.079 \\
\hline DS1 & 0.45 & 0.40 & 0.45 & 0.019 & 0.019 \\
\hline WS2 & 0.32 & 0.068 & 0.32 & 0.38 & 0.38 \\
\hline DS2 & 0.34 & 0.34 & 0.34 & N/A & N/A \\
\hline WS3 & 0.16 & 0.16 & 0.16 & N/A & N/A \\
\hline & WS1 & DS1 & WS2 & DS2 & WS3 \\
\hline (e) & \multicolumn{5}{|c|}{ Rwanda, CvMAE } \\
\hline WS1 & 0.15 & 1.2 & 0.22 & 0.83 & 0.26 \\
\hline DS1 & 0.51 & 0.31 & 0.53 & 0.27 & 0.48 \\
\hline WS2 & 0.33 & 0.81 & 0.35 & 1.1 & 0.50 \\
\hline DS2 & 0.53 & 0.46 & 0.52 & N/A & N/A \\
\hline WS3 & 0.40 & 1.0 & 0.39 & N/A & N/A \\
\hline & WS1 & DS1 & WS2 & DS2 & WS3 \\
\hline (f) & \multicolumn{5}{|c|}{ Rwanda, mean-normalized bias } \\
\hline WS1 & 0.15 & 1.2 & 0.056 & 0.78 & 0.070 \\
\hline DS1 & -0.51 & 0.018 & -0.53 & -0.14 & -0.48 \\
\hline WS2 & -0.0021 & 0.58 & -0.071 & 1.0 & 0.32 \\
\hline DS2 & -0.48 & 0.15 & -0.48 & N/A & N/A \\
\hline WS3 & 0.0004 & 0.95 & -0.06 & N/A & N/A \\
\hline & WS1 & DS1 & WS2 & DS2 & WS3 \\
\hline
\end{tabular}


(a)

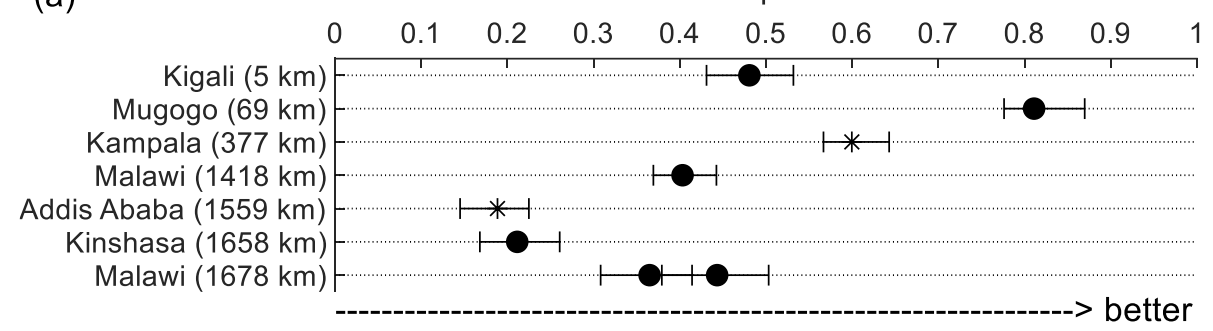

(b)

\section{CVMAE}

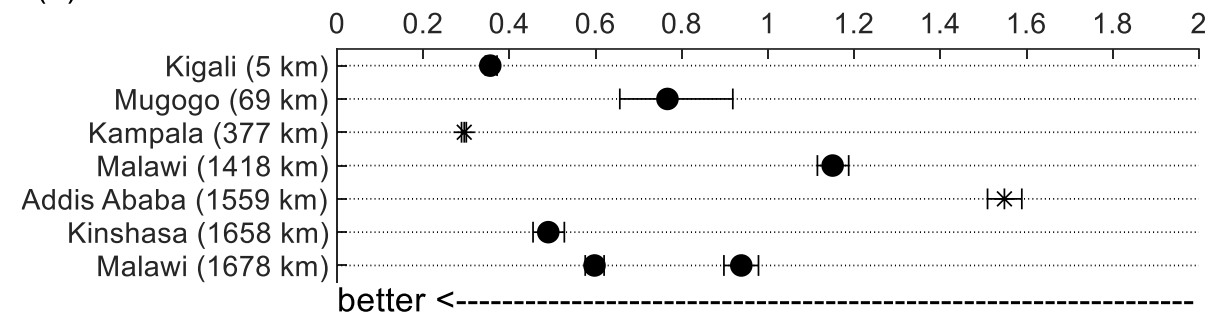

(c)

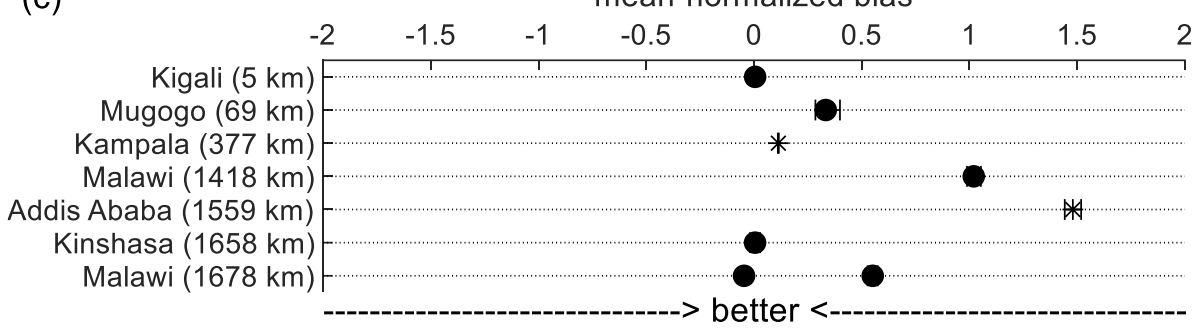

Figure S24: Results corresponding to Fig. 9 for AOD at $470 \mathrm{~nm}$. 